\title{
Influence of Different Load Application Devices on Fracture Resistance of Restored Premolars
}

\author{
Gisele Rodrigues da SILVA ${ }^{1}$ \\ Natércia Rezende da SILVA ${ }^{1}$ \\ Paulo Vinícius SOARES ${ }^{1}$ \\ Ana Rosa COSTA ${ }^{2}$ \\ Alfredo Júlio FERNANDES-NETO ${ }^{1}$ \\ Carlos José SOARES ${ }^{1}$
}

\author{
${ }^{1}$ Biomechanical Research Group, Department of Operative Dentistry and Dental Materials, Dental School, \\ UFU - Federal University of Uberlândia, Uberlândia MG, Brazil \\ ${ }^{2}$ Department of Dental Materials, Piracicaba Dental School, UNICAMP - University of Campinas, Piracicaba, SP, Brazil
}

\begin{abstract}
This in vitro study analyzed the effect of different load application devices on fracture resistance and failure mode of maxillary premolars restored with composite resin. Sixty human maxillary premolars received standardized mesio-occluso-distal cavity preparations and were restored with composite resin. The specimens were randomly divided into 6 groups $(\mathrm{n}=10)$. Compressive loading was applied using 6 different metallic devices: S2: 2-mm sphere; S6: 6-mm sphere; C2: 2-mm cylinder; C6: 6-mm cylinder; WS: wedge shape device; and MAT: individualized metallic antagonist tooth. Data were analyzed statistically using one-way ANOVA and Tukey's test $(\alpha=0.05)$. The failure mode was recorded based on the 4 sequential levels. Statistical analysis revealed that WS presented significantly higher fracture resistance than S6 and C6. No significant difference was found among MAT, C2, S2 and S6. Sphere and cylinder with $6 \mathrm{~mm}$ were similar, with the lowest values of all groups. MAT presented the least number of catastrophic failures while C2, S2 and WS presented the highest. The type of load application device influences significantly the behavior of the teeth-restoration complex during mechanical fracture resistance test.
\end{abstract}

Key Words: fracture resistance, load, biomechanics.

\section{INTRODUCTION}

Dental fracture in posterior teeth has been considered to be a common clinical problem, and its causes have been identified as high impact forces caused by biting on a hard object or uncontrolled contact of opposing teeth (1). Moreover, it is influenced by the anatomic configuration of the tooth, justifying the highest incidence of failures in maxillary premolars (2-4). The majority of premolar fractures occurs at the base of buccal or lingual cusps (2-4). When a significant amount of the tooth structure is lost, there is an increase of the fragility and susceptibility to fracture (4-8).

An important method employed to evaluate the ultimate strength of restored posterior teeth is the compressive load fracture test. This mechanical test type is performed to quantify the influence of different factors involved in restorative procedures (9-11). This test usually produces failure loads that exceed the load limit exerted by the normal stomatognathic system movements (12). In spite of this, higher loading situations can be compared to the situation in which the individual grinds a solid body of small dimensions and the force that would be distributed over the occlusal surfaces of posterior teeth is concentrated on a single tooth (11). Several studies have used a universal testing machine to deliver a compressive load to the occlusal surfaces by means of various metallic devices such as steel sphere (2-11,14-16), steel cylinder (17,19), wedge shape device with a straight (18) and cast metal antagonist tooth $(20,21)$. Some these devices contact only the restorative material (23), others contact the tooth structure, and

Correspondence: Prof. Dr. Carlos José Soares, Área de Dentística e Materiais Odontológicos, Faculdade de Odontologia, Universidade Federal de Uberlândia, Avenida Pará, n¹720, Bloco 4L, sala 4L32, 38400-902 Uberlândia, MG, Brasil. Tel: +55-34-3218-2222. Fax: +55-34-3218-2279. e-mail: carlosjsoares@umuarama.ufu.br 
others contact both the tooth structure and the restorative material. However, the correlation between the device used and the aim of each study is not clearly defined.

The aim of this study was to analyze the effect of different metallic devices employed in the fracture resistance test on the ultimate fracture resistance and failure mode on tooth structures under compressive axial load. The null hypothesis is that the metallic device used to apply load during compressive fracture test has no influence on the fracture resistance and failure mode of the maxillary premolars.

\section{MATERIAL AND METHODS}

Sixty freshly extracted, sound, caries-free human maxillary premolars of similar size and shape indicated for extraction because of periodontal problems or orthodontic treatment, were selected for the study. The study design was approved by the Ethics Committee of the Federal University of Uberlândia, MG, Brazil (Protocol \#211/2005). Calculus and soft tissue deposits were removed with hand scaler. The teeth were cleaned using a rubber cup and fine pumice water slurry and stored in $0.2 \%$ thymol solution (F. Maia Ind. Com., Cotia, SP, Brazil) at $37^{\circ} \mathrm{C}$ for less than 3 months. Tooth crowns were measured with a digital caliper (CD15; Mitutoyo Co., Kawasaki, Honshu, Japan) mesio-distally (MD) and bucco-palatally (BP) to determine the medium size range $(\mathrm{MD}=6.5 \pm 0.5 \mathrm{~mm} ; \mathrm{BP}=8.6 \pm 0.7 \mathrm{~mm})$. The teeth were randomly assigned to 6 groups $(\mathrm{n}=10)$ according to the load application devices: 2-mm diameter steel sphere (S2); 6-mm diameter steel sphere (S6); 2-mm diameter steel cylinder (C2); 6-mm diameter steel cylinder (C6); wedge shape device with a straight active end
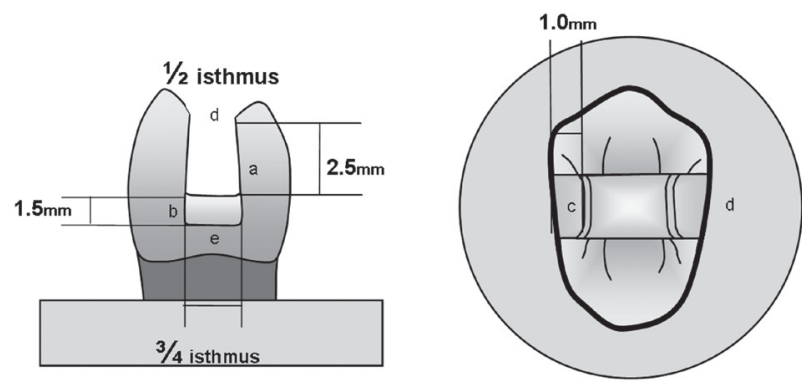

Figure 1. Dimension of cavity preparation design. A: Occlusal box depth $(2.5 \mathrm{~mm})$. B: Axial wall height $(1.5 \mathrm{~mm})$. C: Gingival floor width $(1.0 \mathrm{~mm})$. D: Occlusal box width (half of intercuspal distance at isthmus). E: Gingival floor buccopalatal measurement (equals three fourths intercuspal distance at isthmus).
$1 \mathrm{~mm}$ thick and $7 \mathrm{~mm}$ wide (WS); and individualized metallic antagonist tooth contacting in centric relation of occlusion (1:1) (MAT).

Each tooth was individually fixed in a cylinder so that the roots were embedded up to $2 \mathrm{~mm}$ in polystyrene resin (Aerojet, Santo Amaro, SP, Brazil) below the cementoenamel junction (CEJ). The periodontal ligament was reproduced with a polyether impression material (Impregum F; 3M ESPE, St Paul, MN, USA) (22). Cavities with similar dimensions (Fig. 1) were prepared using a standard cavity preparation machine equipped with reversed conic round-ended diamond burs (\#1151; KG Sorensen, Barueri, SP, Brazil) at high-speed rotation and with continuous air-water spray.

After cavity preparation, the teeth were etched with 37\% phosphoric acid gel (Magic Acid; Vigodent, Rio de Janeiro, RJ, Brazil) for $15 \mathrm{~s}$ and washed with water for $15 \mathrm{~s}$. An one bottle-adhesive system (Adper Single Bond 2; 3M ESPE) was then applied on the cavities with disposable microbrush tips (KG Sorensen), according to the manufacturer's instructions. The adhesive system was light-cured for $20 \mathrm{~s}$ using a halogen light source with $800 \mathrm{~mW} / \mathrm{cm}^{2}$ light intensity (XL 3000; 3M ESPE), maintaining the light-curing guide tip at a distance of 1

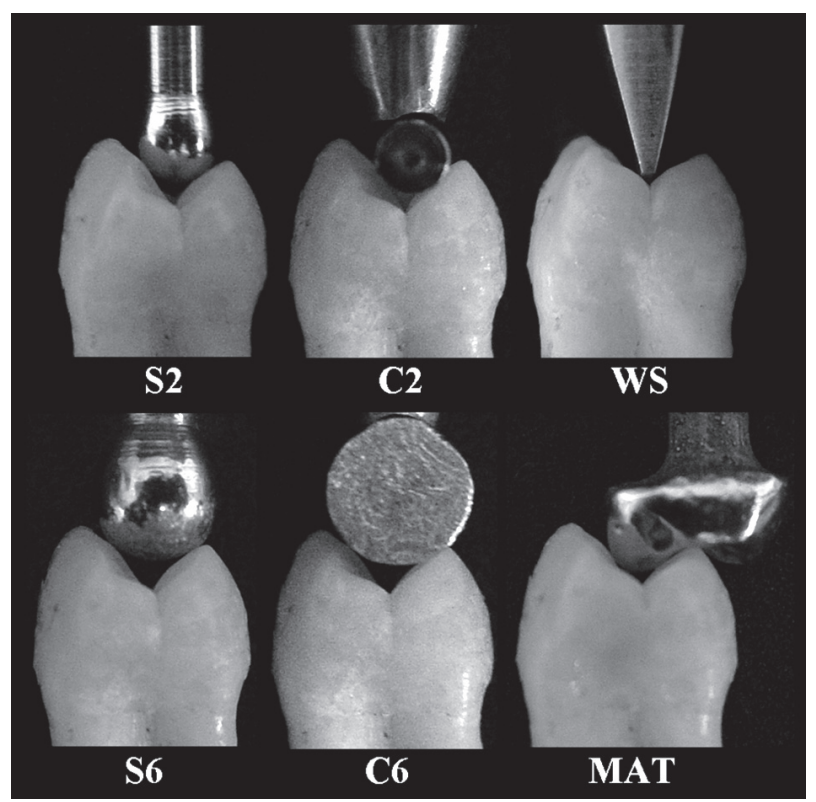

Figure 2. Compressive load application devices. S2: 2-mm diameter steel sphere. S6: 6-mm diameter steel sphere. C2: 2-mm diameter steel cylinder. C6: 6-mm diameter steel cylinder. WS: wedge shape device with a straight active end (1-mm thick and 7-mm wide). MAT: individualized metallic antagonistic tooth, which contacted in centric relation of occlusion (1:1). 
$\mathrm{cm}$. A metal matrix held by a Tofflemire retainer (S.S. White Dental Manufacturing Company, Philadelphia, PA, USA) was placed around the tooth. Incremental technique using composite resin was employed to restore the prepared teeth (Filtek Z250; 3M ESPE). Each increment was light-cured for $40 \mathrm{~s}$. After $24 \mathrm{~h}$ of storage in distilled water at $37^{\circ} \mathrm{C}$, the samples were finished with diamond burs (KG Sorensen) at low speed with air-water spray and polished with aluminum oxide discs (SofLex; 3M ESPE).

The samples were subjected to compressive load at a crosshead speed of $0.5 \mathrm{~mm} / \mathrm{min}$ in a mechanical testing machine (DL 2000; EMIC, São José do Pinhais, PR, Brazil). Compressive loading was applied using the six metallic devices described before and illustrated in Figure 2: S2, S6, C2, C6, WS and MAT. The last device was made using a semi-adjustable articulator, where the wax patterns of the antagonist tooth were made and then cast in a Ni-Cr alloy (Kromalit; Knebel, Porto Alegre, $\mathrm{RS}$, Brazil). Ten antagonist teeth were made, one per specimen.

The load required $(\mathrm{N})$ to cause fracture was recorded by a $500 \mathrm{kgf}$ load cell hardwired to software (TESC; EMIC). The results of the fracture resistance were submitted to statistical analysis by one-way ANOVA and Tukey's test $(p<0.05)$. The fractured samples were evaluated in a stereomicroscope (Leica MZ10F; Leica Mikrosysteme Vertrieb, GmbH Bensheim, $\mathrm{HE}$, Germany) to determine the failure mode in each sample, following as reference the model classification according to the one proposed by Soares et al. (11). The four classification levels were: (I) isolated fracture of the restoration; (II) restoration fracture involving small tooth portions; (III) fracture involving more than half the tooth without periodontal involvement; (IV) fracture with periodontal involvement. The fracture patterns were presented as percentages.

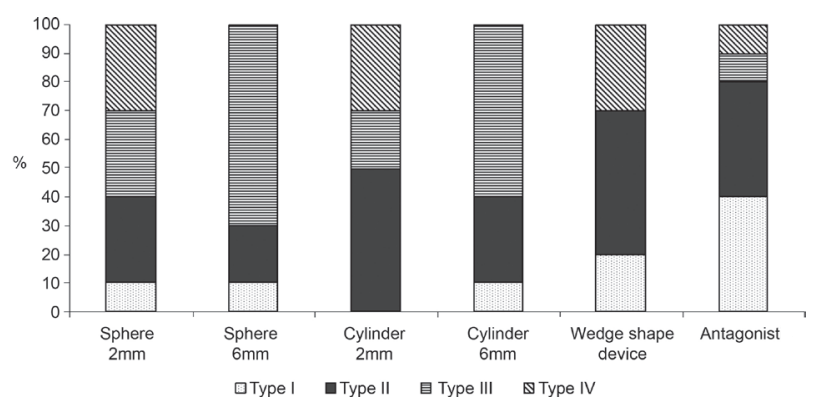

Figure 3. Fracture mode classification.

\section{RESULTS}

The mean, standard deviation and statistical category of the forces $(\mathrm{N})$ applied to cause failures for each tested group are in Table 1. The one-way ANOVA showed that there were significant differences among groups $(\mathrm{p}=0.00)$. Tukey's test $(\mathrm{p}<0.05)$ showed that the WS group presented higher fracture resistance than the S6 and C6 groups. No statistically significant differences were found among MAT, C2, S2, and S6 groups. Moreover, the teeth loaded with S6 and C6 presented similar fracture resistance values and were the lowest compared with other groups.

The failure modes are presented in Figure 3. S6 and $\mathrm{C} 6$ caused a greater number of type III dental failure. The MAT group showed the least number of catastrophic failures, resulting in a greater incidence of type I and II failures, while C2, S2 and WS groups induced higher number of catastrophic fractures (type IV), compared with other groups.

\section{DISCUSSION}

The tested null hypothesis in this study was rejected. The load application device type influenced in the fracture resistance values and in the failure mode of maxillary premolars restored with composite resin. The fracture resistance tests are largely used (1-11,13-23) and are an important source of information, indicating which component is more fragile: the restoration, the dental structure or the adhesive interface. However, when performing mechanical tests, there is a number of factors that could interfere on the resistance to fracture, such as the tooth embedding method (20), the crosshead

Table 1. Mean values and standard deviations of the force (N) necessary to cause fracture.

\begin{tabular}{lc}
\hline Group $(\mathrm{n}=10)$ & Resistance fracture means (SD) \\
\hline Wedge shape device & $1,047.0(308.0)^{\mathrm{a}}$ \\
Antagonistic tooth & $928.0(216.0)^{\mathrm{ab}}$ \\
2-mm cylinder diameter & $859.0(303.0)^{\mathrm{ab}}$ \\
2-mm sphere diameter & $827.0(332.0)^{\mathrm{ab}}$ \\
6-mm sphere diameter & $588.0(196.0)^{\mathrm{bc}}$ \\
6-mm cylinder diameter & $461.0(157.0)^{\mathrm{c}}$ \\
\hline
\end{tabular}

Different letters indicate statistically significant difference ( $<<0.001$; Tukey's test). 
speed and type of load application device (1). Many studies that evaluate the behavior of the dental structures to the compressive load using different types of load application devices (1). The variation of these devices influences directly the obtained results, as observed in this study. Thus, it is questionable to compare studies that employ different devices, which is a common finding in the literature (Table 2).

The shape and the diameter of the load application device define the contact with the tooth or the restorative material. S6 and C6 contact the cusp tipping of premolar. It results in tensile stress on the adhesive interface, requesting the restorative material bond. On the other hand, devices that contacted only the restorative material, e.g. WS, S2 ans $\mathrm{C} 2$, modulated the fracture resistance. This property is based on the intrinsic resistance of the material that is inserted in the intra-coronay cavity. Therefore, the composition, the ultra-structural configuration and the physical properties of the material interfere in the quantity and quality of the resultant stress on the adjacent dental structure.

C6 contacts the entire occlusal Soares et al. (11) 6-mm steel sphere

$90 \quad 10$

Bitter et al. (13)

$$
3.5-\mathrm{mm} \text { steel ball }-30^{\circ}
$$

Habekost et al. (14)

$$
\text { 3-mm/10mm steel sphere }
$$

Oliveira et al. (16)

Ausiello et al. (17)

Moritmoto et al. (18)

de Freitas et al. (19)

Purk et al. (20)

Soares et al. (21)

Antagonist metallic tooth

$80 \quad 10$

surface. Thus, the compressive loading provides cuss deflection that results in fractures involving mainly the coronal portion without periodontal involvement (Fig. 3). Also, lower load values than those obtained with the other tested devices were observed in this case. The contact of WS, S2 and C2 presented more catastrophic failure mode, with periodontal involvement in $30 \%$ of the samples (Fig. 3). These devices contacted only the restorative material, compressing it inside the tooth. Since the composite resin and the dentin have similar modulus of elasticity, there is stress transmission to coronal and root dentin and it could induce fracture with root involvement. On the other hand, the MAT device, which contacted 
in occluding centric relation, resulted in less amount of type IV fractures (Fig. 3).

In this way, the ideal device that seems to be more similar to the occlusal loading that occurs in the oral cavity, must be specific according to the occlusal anatomy of the sample, as reproduced in the MAT group. The use of an individualized metallic antagonistic tooth resulted in high fracture resistance and more favorable failure modes. However, the fracture resistance tests employ high number of samples that vary from 4 to 25 samples per group. This sample amount is justified by the variability of the crown dimension and of the ocoronal-radicular form and anatomy of the tooth. In fact, the high cost and greater difficulty for fabrication of the individual device would make the use of this device impracticable, especially in studies that evaluate the fracture resistance using more than 100 samples $(4,5,10,13-15,19)$. Therefore, the definition of the form and dimension of load application device must be determined according to the study objective. Smaller devices that contact only the restoration seems to be the best option when the objective is to analyze the resistance of the dental structure as a function of the recovery characteristic of the material. On the other hand, when the main objective is to analyze the resistance of the dental remnant, the contact with devices of greater diameter it is more adequate because they will contact only the dental structure.

Nevertheless, studies evaluating the resistance to fracture of teeth with composite restorations present controversial results. Some of them reached similar resistance values to sound teeth $(3,6)$, lower resistance values has also been reported (18) while others found higher resistance $(7,11,14,19)$ than to sound teeth. Probably the study that recorded values for direct composite restoration lower than sound teeth employed a loading device with a greater diameter than the cavity preparation. Thus, the contact occurred only on the tooth structure $(8,18)$. On the other hand, the studies that recorded resistance values higher than sound teeth employed loading devices smaller than the cavity preparation, thus the contact occurred only on the restorative material $(3,19)$. Studies that aim to test coverage with composite materials should use both types of metallic devices, one of small size that contacts the restoration and the other one of larger size that contacts only the tooth. This was observed in the study by Habekost et al. (14), who tested the influence of ceramic coverage by two different compressive axial load using two steel balls ( 3 and $10 \mathrm{~mm}$ in diameter). If it is used to test composite resin restoration with only the larger device, the results surely will be higher for coverage because this material presents less stiffness than enamel and dentin. On the other hand, if a smaller metallic device had been used, similar resistance values are expected because in the groups with or without cusp coverage the contact would occur only on the composite resin.

The test used in the present study does not simulate the reality of the clinical situation, as the failure occurs primarily due to fatigue. However, this methodology is largely employed in the literature and it is an important source of information about which component is more fragile. In addition, the most important contribution of this study is the relevance that must be given to the method used for load application in order to validate the comparison with different investigations. Other aspects should be analyzed in more details, as the cross-head speed, configuration of the tooth root and inclination of the sample positioned in the universal testing machine. Despite the great source of information and importance of in vitro fracture resistance test to determine biomechanical behavior in a short time and low cost, the real performance of restorations can only be determined by clinical trials. In conclusion, the type of load application device influenced significantly the behavior of the tooth-restoration complex during in vitro mechanical fracture resistance test.

\section{RESUMO}

Este estudo avaliou o efeito de diferentes tipos de dispositivos de aplicação de carga na resistência à fratura de pré-molares superiores restaurados com resina composta. Sessenta pré-molares humanos receberam preparo mésio-ocluso-distal padronizado e as cavidades foram restauradas com resina composta. As amostras foram aleatoriamente divididas em 6 grupos $(n=10)$. Carregamento de compressão foi realizado usando seis diferentes dispositivos metálicos de aplicação de carga: S2 e S6: esfera de $2 \mathrm{~mm}$ e $6 \mathrm{~mm}$ de diâmetro respectivamente; $\mathrm{C} 2$ e C6: cilindro de $2 \mathrm{~mm}$ e $6 \mathrm{~mm}$ de diâmetro respectivamente; WS: lâmina de faca e MAT: antagonista individualizado em metal. Os resultados foram submetidos à análise de variância e teste de Tukey $(\mathrm{p}<0,05)$. O modo de falha foi classificado em 4 níveis e estão apresentado em porcentagem. O dispositivo WS resultou em maior resistência a fratura de prémolares que S6 e C6. Não houve diferença estatística entre os grupos MAT, C2, S2 e S6. Menor resistência foi verificada com o uso de $\mathrm{S} 6$ e C6. O dispositivo MAT resultou em menor número de falhas catastróficas enquanto nos grupos C2, S2 e WS essas falhas foram significativas. O tipo de dispositivo de aplicação de carga influenciou significativamente no comportamento do complexo dente-restauração durante o teste de resistência à fratura. 


\section{ACKNOWLEDGEMENTS}

The authors are indebted to FAPEMIG and CNPq for the financial support.

\section{REFERENCES}

1. Burke FJ. Tooth fracture in vivo and in vitro. J Dent 1992;20:131139. Review.

2. Kivanç BH, Alaçam T, Görgül G. Fracture resistance of premolars with one remaining cavity wall restored using different techniques. Dent Mater J 2010;29:262-267.

3. Mohammadi N, Kahnamoii MA, Yeganeh PK, Navimipour EJ. Effect of fiber post and cusp coverage on fracture resistance of endodontically treated maxillary premolars directly restored with composite resin. J Endod 2009;35:1428-1432.

4. Nam SH, Chang HS, Min KS, Lee Y, Cho HW, Bae JM. Effect of the number of residual walls on fracture resistances, failure patterns, and photoelasticity of simulated premolars restored with or without fiber-reinforced composite posts. J Endod 2010;36:297301.

5. Meng QF, Chen YM, Guang HB, Yip KHK, Smales RJ. Effect of a ferrule and increased clinical crown length on the in vitro fracture resistance of premolars restored using two dowel-and-core systems. Oper Dent 2007;32:595-601.

6. Dalpino PH, Francischone CE, Ishikiriama A, Franco EB. Fracture resistance of teeth directly and indirectly restored with composite resin and indirectly restored with ceramic materials. Am J Dent 2002;15:389-394.

7. Nothdurft FP, Seidel E, Gebhart F, Naumann M, Motter PJ, Pospiech PR. The fracture behavior of premolar teeth with class II cavities restored by both direct composite restorations and endodontic post systems. J Dent 2008;36:444-449.

8. Soares PV, Santos-Filho PC, Martins LR, Soares CJ. Influence of restorative technique on the biomechanical behavior of endodontically treated maxillary premolars. Part I: fracture resistance and fracture mode. J Prosthet Dent 2008;99:30-37.

9. Burke FJ, Wilson NH, Watts DC. Fracture resistance of teeth restored with indirect composite resins: the effect of alternative luting procedures. Quintessence Int 1994;25:269-275.

10. Monga P, Sharma V, Kumar S. Comparison of fracture resistance of endodontically treated teeth using different coronal restorative materials: an in vitro study. J Conserv Dent 2009;12:154-159.

11. Soares CJ, Martins LR, Fonseca RB, Correr-Sobrinho L, Fernandes Neto AJ. Influence of cavity preparation design on fracture resistance of posterior Leucite-reinforced ceramic restorations. J Prosthet Dent 2006;95:421-429.

12. Gibbs $\mathrm{CH}$, Mahan PE, Mauderli A, Lundeen HC, Walsh EK. Limits of human bite strength. J Prosthet Dent 1986;56:226-229.

13. Bitter K, Meyer-Lueckel H, Fotiadis N, Blunck U, Neumann K, Kielbassa AM, et al.. Influence of endodontic treatment, post insertion, and ceramic restoration on the fracture resistance of maxillary premolars. Int Endod J 2010;43:469-477.

14. Habekost L de V, Camacho GB, Pinto MB, Demarco FF. Fracture resistance of premolars restored with partial ceramic restorations and submitted to two different loading stresses. Oper Dent 2006;31:204-211.

15. Elayouti A, Serry MI, Geis-Gerstorfer J, Löst C. Influence of cusp coverage on the fracture resistance of premolars with endodontic access cavities. Int Endod J 2011;44:543-549.

16. Coelho-de-Souza FH, Rocha Ada C, Rubini A, Klein-Júnior CA, Demarco FF. Influence of adhesive system and bevel preparation on fracture strength of teeth restored with composite resin. Braz Dent J 2010;21:327-331

17. Oliveira JP, Cochran MA, Moore BK. Influence of bonded amalgam restorations on the fracture strength of teeth. Oper Dent 1996;21:110-115.

18. Ausiello P, De Gee AJ, Rengo S, Davidson CL. Fracture resistance of endodontically-treated premolars adhesively restored. Am J Dent 1997;10:237-241

19. de Freitas CR, Miranda MI, de Andrade MF, Flores VH, Vaz LG, Guimarães C. Resistance to maxillary premolar fractures after restoration of class II preparations with resin composite or ceromer. Quintessence Int 2002;33:589-594.

20. Morimoto S, Vieira GF, Agra CM, Sesma N, Gil C. Fracture strength of teeth restored with ceramic inlays and overlays. Braz Dent J 2009;20:143-148.

21. Purk JH, Eick JD, DeSchepper EJ, Chappell RP, Tira DE. Fracture strength of Class I versus Class II restored premolars tested at the marginal ridge. I. Standard preparations. Quintessence Int 1990;21:545-551.

22. Soares CJ, Pizi EC, Fonseca RB, Martins LR. Influence of root embedment material and periodontal ligament simulation on fracture resistance tests. Braz Oral Res 2005;19:11-16.

23. Magne P, Boff LL, Oderich E, Cardoso AC. Computer-aideddesign/computer-assisted-manufactured adhesive restoration of molars with a compromised cusp: effect of fiber-reinforced immediate dentin sealing and cusp overlap on fatigue strength. J Esthet Restor Dent 2012:24:135-146.

Received November 17, 2011 Accepted August 21, 2012 